\title{
Pakistan Video industry: Creating equilibrium through re-calibration of the roles and powers, for future commercial growth
}

Page 36

Received: 25 Aug 2019

Revised: 19 Nov 2019

Revised: 25 June 2020

Accepted: 30 Aug 2020
NBR

NUST Business Review NBR-19-0013

Vol. 02 , No. 01

10, 2020

pp. $36-43$

(c) NUST Business School

\author{
Hassan Waqar Raja \\ Consultant, Islamabad, Pakistan
}

\begin{abstract}
:
Pakistan's video industry is faced with existential challenges. This note presents an industry overview through a practitioner's perspective, and discusses both global trends and technologies in Pakistan's context. It goes on to make recommendations on how specific actions can transform our industry into an instrument of national power and commercial value.
\end{abstract}

Key Points:

- Pakistan's video market is a combination of 100 Million individual connections (TVs and mobile devices). This view is different than the regulatory focus on traditional TV Households

- Growth of our market is linked to recalibration of the current regulatory frameworks. Pakistan should open its doors to foreign investments in content production $\mathcal{E}$ broadcast.

- Distribution segment of the video industry is its lynchpin. Nationwide distribution licenses with hybrid offering (traditional $\mathcal{E}$ OTT) are likely to be commercially successful in future.

- Pakistan must grow its video industry as an instrument of national power. For doing so, it must create a combination of foreign investments, indigenization of skillset and technology through industry-academia partnerships, and an enabling regulatory environment.

Keywords: Pakistan, Media, Video Distribution, OTT (Over The Top), Content Production.

Paper type: Industry Note 
Pakistan's video industry faces a series of existential challenges today. More importantly, some of them threaten to undermine its identity ${ }^{1}$ as an independent national industry. The spheres of digital, video (traditionally known as electronic media) and, print media overlap more closely than ever. Technology evolution has transformed traditional print media into web and app based

NBR

2,1

Page 37 aggregator of both video and written content. In our market cross-ownership of print and video entities has created large and powerful stakeholders across the different regulatory boundaries. Similarly, digital media ${ }^{2}$ platforms are coming in direct competition with traditional video players and simultaneously the latter uses the former for their content monetization ${ }^{3}$ (NY Times, 2018). Additionally, blurring of boundaries between the traditional roles of content producers, broadcasters and distributors in this day and age of Netflix and other OTT players have given rise to multiple challenges within the local industries across the globe (NY Times, 2018).

The fundamental question for the video industry in Pakistan is; how to improve the return on any investments, past and current, and how to monetize existing infrastructure and content assets? According to Census 2017, Pakistan's population has crossed 207 million individuals ${ }^{4}$ (PBS, 2019). With an estimated 34 million households by the end of 2019, of which there are estimated to be 25 million TV households, our video consumer market is one of the largest in Asia. However, it is also one of the most under- developed and least progressive as per last published data of PEMRA (PEMRA 2015- 2019)5. Pakistan has an active mobile subscriber base of over 69 million 3G/4G connections and total 71 million $^{6}$ broadband users (both 3G/4G and Fixed Broadband) (PTA, 2019) 7 . At present, total video connections (a combination of TV and mobile device video users) in the country are estimated to be over 100 million users ${ }^{8}$. However, our video industry planners are still focused on the traditional definition of a TV household. In contrast, newer technologies have enabled mobile phones and tablets for video viewing, and given birth to notions of

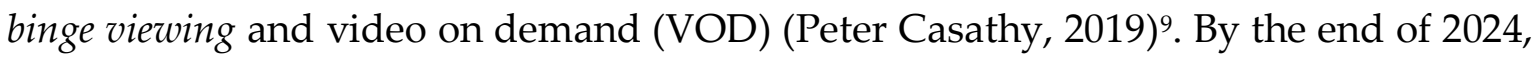
at the current growth rate, Pakistan's video market size is likely to be well above 150 million video connections. This will make our video market bigger than the total population of some of the smaller countries in our region. Notably, over $70 \%$ of these new video connections lie out- side the purview of the Pakistan Electronic Media Regulatory Authority (PEMRA) ${ }^{10}$.

Globally, large markets have adopted a single regulatory framework for both telecom and traditional video industries. In our neighbourhood, Telecom Regulatory

\footnotetext{
${ }^{1}$ Identity is explained as a set of unique characteristics, effectiveness of an entity and its visibility across the subscriber spectrum, and its ability to commercially sustain itself

2 Social media platforms like YouTube, twitter, Facebook

${ }^{3}$ Diversification of revenue stream by re-offering of content over YouTube, Facebook and other platforms

4 Pakistan Bureau of Statistics 2017

5 Statistics available in PEMRA Report 2015- 2018

${ }^{6}$ PTA Statistics Jun 2019 (www.pta.gov.pk)

7 There is an overlap between broadband and 3G/4G users. Its extent is not fully known at this point but it presents the point that video market lies outside traditional video production, broadcast and distribution platforms as well. 826 million TV Households and 62 million Broadband users (3G/4G and Fixed Broadband) users with an estimated additional 7 million undocumented TV connections ( $2^{\text {nd }}$ and $3^{r d}$ TV sets at homes and commercial installations) ${ }^{9}$ https://www.forbes.com/sites/petercsathy/2019/08/15/disneys-12-99-shot-across-netflixs-bow/

${ }^{10}$ Mobile Connections are regulated by PTA. Content distribution on the mobile devices i.e. 'Mobile TV' services is regulated through PEMRA Licensing.
} 
NBR

2,1

Page 38

Authority of India (TRAI), and elsewhere; British OfCom (Office of Communications) and US FCC (Federal Communications Commission) are examples of a single regulator for the video and telecommunications industries. In the face of growing technology convergence, merger of the telecom and media regulators is inevitable for effective industry management.

India's media and entertainment industry's size was approx. USD twenty two billion (US\$ 22 billion) in 2018 (IBEF, 2019) ${ }^{11}$, and had over eight hundred channels in different categories. This market is highly resilient and it is expected to grow to USD forty billion (US\$ 40 billion) by 2023, with its video on demand (VOD) market to add another USD five billion (US\$ 5 billion), (Lata Jha, 2018). Globally, it is one of the largest producer and consumer of content. Its vicinity poses a direct threat to our market in terms of our market's ability to commercially compete. Indian industry has its eyes set on global markets, and is creating content for all screen sizes $^{12}$. Indian market has experienced healthy local growth and this is directly attributed to the digitization of their distribution networks and introduction of direct- to- home (DTH) licensing. These changes have completed the traditional revenue lifecycles for different players and have led to multiple revenue streams for the traditional content producer and broadcaster.

In contrast, on our side of the border, broadcast market consists of around eighty-eight private channels, thirty-seven foreign channels with permission to land in Pakistan (Landing Rights permissions) and nine state broadcaster channels (PEMRA, 2019) ${ }^{13}$. Our private channels are mostly free-to-air (FTA) with television advertisements as primary sources of income. The total volume of our broadcast market is assessed to be around USD 250 million per annum. This is miniscule compared to the regional competition and it is projected to remain stagnant in the near future.

In 2018-19, PEMRA auctioned sixty-four TV channel licenses. In view of the revenue stagnation, addition of these new players is likely to lead to congestion in an already tight commercial space where individual share of the advertisement revenue shall shrink further (Fawad Chaudhary, 2019). Mergers and acquisitions are not straightforward in our industry because of regulatory restrictions. A likely outcome of these factors will be increased contrast in the content offering of large and small players i.e. smaller players' reliance on low cost foreign content (dubbed) from South Korea, Turkey, etc.

Our traditional video distribution landscape (cable TV, IP TV, FTTH, MMDS) in general continues to be riddled with a combination of legacy systems and operational inefficiencies, localized political challenges, and cash flow constraints. Distribution networks are the lynchpin for growth of any video industry. Its growth and new investments in infrastructure are critical for provision of other value-added services associated with modern day Pay-TV industry.

Our current distribution licensing is based on a localised format i.e. licences are awarded for small geographical (urban and rural) areas with subscriber numbers as license classification criteria. In most cases overlap between different operators is rare in distribution. The only exceptions are PTCL's IPTV license and recently awarded first DTH license.

11 https://www.ibef.org/industry/media-entertainment-india.aspx

12 Cinema, TV and Mobile Devices

13 Statistics correct up to Jul 2019 
Distribution infrastructure is a commercially prohibitive proposition in a low ARPU14 market like Pakistan. Secondly, our regulatory frameworks on distribution do not provision for corporate financing i.e. licenses are non-transferable or assignable and therefore bank loans cannot be obtained on the licenses. Both these

NBR

2,1

Page 39 issues restrict growth and investments in this area. This has enabled current distributors, as the gatekeepers to the subscribers, to gain political clout over other segments of the industry. As a result, overall subscriber experience cannot be improved. PEMRA's efforts to change the current situation are notable, but not sufficient to drive change.

Furthermore, distribution licenses have provisions for in-house thematic channels. The total number of in-house channels (for 1,100+ Head- end licenses), today, is more than the total formally awarded mainstream TV channel licenses in the country. This is a hard- to- regulate commercial space. Revenues earned from local advertisements on these channels often remain masked from the regulator. These channels are often found to be in violation of copyrights, piracy, and other laws. These are, therefore, the sources of commercial loss to larger regulated TV channels and content producers. Pakistan's content production industry currently lies outside the purview of PEMRA regulations. Content production infrastructure in the country in most cases is vertically integrated/owned by the large broadcasters. This integration is commercial short termism. It has impacted the growth of our industry. Firstly, there is a focus on commercial returns and race for viewership e.g. mainstreaming of stage drama on all major channels. Such lop-sided focus has its expected entrapments where cultural, informational, educational and scientific, and regional content has been side-lined. Secondly, such vertical integration limits the potential of growth for independent production houses and therefore restricts the much-needed plurality of ownership and thought in the content development.

In summary, Pakistan's video industry is commercially shrinking with an overall stagnant ARPU. Amongst many challenges in the current landscape is the dearth of empirical studies and publications on the industry. Higher education and vocational training institutions in partnership with the regulator can play a major role in supporting the industry. Arrival of OTT has challenged the traditional boundaries between different segments. These boundaries are fast disappearing in favour of a larger integrated video enterprise. In our case OTT based pilferage of foreign content directly impacts the regulation and commercial aspects of our own industry. In the short-term, rise of these vertically integrated video enterprises will be the dominant market force for non-traditional subscribers, particularly millennial. However, in the end, multiple large vertically integrated enterprises will give rise to the need for last-mile third party content aggregators. This will be needed since a subscriber cannot and will not be able to acquire multiple subscriptions from different services. In our market, distribution licensee has traditionally been the content aggregator. Rise of this vertically integrated enterprise will benefit and cement our distributor's position but this requires PEMRA's support through favourable regulation. Early signs of rising role and significance of distributor as the last-mile content aggregator are already apparent in the Indian market (Sudhir Chowdhary, 2019). Our video industry, as part of the larger media industry, requires a commercial stimulus that can be introduced through a comprehensive review of

${ }^{14}$ ARPU: Average Revenue Per User 
the regulation.

Primarily, we require a change in our national mind-set. We must move away from a fear driven reactive approach to an open sky policy for our video industry, where competition and offering should be determinants of both price and perceived quality.

We must capitalize on the large captive home market as well as the regional markets with similar cultural leanings and language. Changes in the current

NBR 2,1

Page 40 regulatory environment should be enabled as a combination of parallel actions with their ultimate convergence on a single goal of growing our video market commercially and reaching foreign markets. For achieving this objective, following must be undertaken:

\section{Regulatory Environment (Setting up of a commercially favourable environment):}

Pakistan should open its video industry to foreign majority ownership in the content production and broadcast segments. This will bring in much needed investments as the current USD- PKR parity is favourable for foreign investments. Furthermore, there is a need to regulate commercial content production licenses in Pakistan to prevent vertical integration between content production and broadcast. Content producer segment needs to be empowered and made independent of the broadcasters. Such regulation will also create a formal mechanism for the provisioning of government support in terms of subsidies, protection measures from issues like piracy, better regulation, and subsequent content development.

Furthermore, foreign channels interested to enter the Pakistani market should be allowed to do so directly. Current regime of landing rights permissions is unnecessarily complex and creates unwanted inefficiencies in the commercial and regulatory relationships. In the best commercial interests, we must make larger global players direct stakeholders. This will also encourage local content production. Moreover, PEMRA should not allow foreign ownership and control in the distribution segment of the industry. This is important to address security concerns, retaining control, and effective management of the industry. Convergence of technology is an on-going challenge in dual regulatory landscape for the local video distributors i.e. PEMRA and PTA. Merger of the two regulators is much needed and has been a matter of intense debate in the early days of the current political government. It is a complex and longitudinal affair running across various political, policy, and operational issues and unlikely to happen anytime soon, unfortunately.

PEMRA must review the OTT framework for Pakistan in light of its regulations rather than following international practice alone. Both are diametrically apart and existence of two different models in Pakistan is going to damage the overall industry. OTT should be introduced by keeping in view the existing licensing regulations that restrict foreign ownership and control. One possible approach to this is allowing current and future large distributors ${ }^{15}$ to also become web based content aggregators and distributors. This initiative will see a likely alliance between the medium sized distributors and ISPs at both the local and the national levels. Foreign OTT players and content syndication setups are then likely to sign-up with the local aggregator/distributor, which in turn will be responsible for compliance with

15 PEMRA must consult larger players and create a standard and a framework for differentiating between different distributors and also for creating Quality Standards 
NBR

2,1

Page 41

regulatory and other national requirements. This is critical to deal with the fast emerging challenge of online piracy. Additionally, the regulator must take immediate steps for converting existing and large distribution licenses into entities that are ready for corporate/project financing. This will be instrumental in introducing newer technologies and upgrading existing infrastructure.

Furthermore, regulatory purview of PEMRA should be extended to the development of the support industries, namely, manufacturing and assembly of equipment (TV sets, set top boxes and other related equipment) and creation of academic and vocational programs with the help of the higher education and training institutions in the country. Firstly, this is to address the creation of national technology standards related to video delivery for the whole value chain. Part of it should be creation of quality of service standards for improving subscriber experience across all platforms. Secondly, PEMRA should pay attention towards the creation and enforcement of standards on contents i.e. its acceptability and suitability for different audience segments. Lastly, creation of a local workforce is needed for future indigenization of foreign knowledge and skillset that will arrive in Pakistan through proposed opening of market to foreign players.

\section{Content Landscape:}

Pakistan's content requirements are unique, where nationalism, religion, ethnicity, local culture, and language are the key variables. Localization of content through preferably production and syndication are required. Our content production has to evolve from single-minded broadcaster specific focus to that of creation of a digital video property for multiple mediums. This is critical for their commercial sustenance and success. This will project and promote our country, industry, culture, and identity outside Pakistan on alternate platforms (Netflix, IFlix etc.) without a dependence on local broadcasters. This cannot happen without foreign investment and knowledge transfer. This approach is a doctrinal anti-thesis to current focus on use of low cost foreign content. Our market is large enough to sustain a vibrant content production. However, it needs reinforcements in the form of strong laws on piracy and prosecution of the guilty.

\section{Distribution Landscape:}

Regulatory emphasis on distribution landscape should be on top of the priority ladder. A landscape of over four thousand cable operators is not sustainable from regulatory and commercial perspectives. Amalgamation of smaller players is necessary for creating economies of scale and for regaining complete regulatory control. This is a highly politicized arena and the Achilles' heel for the whole video industry. Multi-faceted political and regulatory challenges can also be set aside through introducing newer regimes like Headend in the Sky (HITS) ${ }^{16}$ and allowing interconnect for larger licenses like direct-to-home (DTH). Large distribution operations require extensive funding and has significant risks associated with it. Therefore, it is essential that regulatory framework is revisited for allowing corporate and project financing in this arena. Similarly, formation of consortiums should be allowed in this segment.

${ }^{16}$ Only for Large Distributors i.e. DTH where certain standards of encryption, operational efficiencies, and apolitical business objectives are visible and effectively managed 
PTA licensees like ISPs and Telecom Operators are apparent contenders for the traditional cable operators' business. In some cases, both ISPs and cable operators are working in tandem in their areas i.e. video and internet services as a single package. Push for digitisation will either amalgamate smaller players into

NBR

2,1

Page 42 larger consortiums and/or purge non-viable operators. Other licenses like DTH/HITS can potentially occupy the newly created commercial space. The underlying idea in this scheme of actions is not to undermine the existing players but to improve the subscriber experience through enhanced competition and thereby yielding an improvement in ARPU.

\section{Actions in other areas and industries:}

Inexpensive locally produced equipment is necessary for growth of our video industry. This is particularly important in view of the increasing USD- PKR parity and imposition of new duties on imported equipment. Local industrial parks (media cities) should be created at two locations, in Lahore and Karachi, where the different commercial players should be housed. Industry-academia linkages should be setup for training a dedicated workforce for the video industry. Academia can also play an important role in different areas identified in the aforementioned paragraphs.

The proposed series of parallel actions is akin to creation of Open- Sky for content producers and broadcasters. These commercial incentives are the key to restricting piracy and pilferage of foreign content and distribution platforms in the country. Strategic control of the overall industry will be exercised through distribution networks. Currently, large global content producers and broadcasters have coupled our market with the Indian market. They are unlikely to produce dedicated content or invest in our market if they do not see a sound commercial case and are not made direct stakeholders.

Pakistan must grow its video industry into an effective instrument of national power. Our market size is sufficient to create a complete self-sustaining media ecosystem. Commercial value and return are the fundamental to the success and sustenance of our industry. It needs protection from foreign content and operators'. Similarly, it requires internal stimulus in the form of change in regulation to encourage new local and foreign investors and corporate financing. Focusing on content production and distribution segments is the way to go!

\section{References}

Peter Casathy (2019), Disney's \$ 12.99 Shot Across Netflix Bow, Forbes, https://www.forbes.com/sites/petercsathy/2019/08/15/disneys-12-99-shot-across-netflixsbow/Indian Media and Entertainment Industry Report ( Septemeber 2019), available on India Brand Equity Foundation (IBEF), https://www.ibef.org/industry/mediaentertainment-india.aspx

Fawad Chaudhary (2019), Media must revamp models to remain independent: Fawad Chaudhry, 13 Jan, 2019, available on https://www.dawn.com/news/1457292

Lata Jha (2018), Video Streaming market in India to reach \$5 Billion by 2023, BCG Report, 21, Nov 2018. Available on https://www.livemint.com/Consumer/P9ZSN91tXV9eWM3mXRndrJ/Video-streaming-marketin-India-to-reach-5-billion-by-2023.html

New York Times (NY Times), (2018), Where countries are Tinderboxes and Facebook is a match, 21- 04- 2018, (https://www.nytimes.com/2018/04/21/world/asia/facebook-srilanka-riots.html) 
NBR

\section{2,1}

Page 43

PBS (2019), Population Census, http://www.pbs.gov.pk/content/population-census

PEMRA (2015- 2019), PEMRA Annual Report, available on www.pemra.gov.pk

PEMRA (2019), Landing Rights Licenses Details available on http://58.65.182.183/pemra/pemgov/wpcontent/uploads/2015/09/List_of_Licences_Issued_LR.pdf

PEMRA (2019), Satellite TV Channel Licences details available on http://www.pemra.gov.pk/ Licensing/ Satellite TV

PTA (2019), Telecom Indicators (Sep 2019) available at https://www.pta.gov.pk/en/telecomindicators

Rapid TV News (2018), Amazon Prime Tops 26 Million US Viewers, available on https://www.rapidtvnews.com/2018031651314/amazon-prime-tops-26mn-usviewers.html\#axzz65h32mlEB

Sudhir Chowdhary (2019), Tata Sky Binge: Stream content from Hotstar, Eros Now and More, 11 Jul, 2019, Available on https://www-financialexpress-

com.cdn.ampproject.org/c/s/www.financialexpress.com/industry/technology/tata-skybinge-a-new-dimension-to-tv-viewing-stream-content-from-hotstar-eros-now-andmore/1639924/lite/

\section{About the Author: Hassan Waqar Raja}

H W Raja is an alumnus of Military College of Signals (MCS). He has served on the Faculty of NUST Business School (NBS), National University of Sciences and Technology, Islamabad, Pakistan, and has also been the Head of Centre for Executive Development (CED). He has been associated with the Media Industry for over five years, and previously led the team that was awarded Pakistan's first Direct to Home (DTH) license in Feb 2019. He has previously worked in UK and Pakistan in private, public and social sectors. Currently, he is working as Consultant Technology \& Media Affairs at Bahria Town, Pakistan.

The Corresponding Author Mr Raja can be contacted on hwraja@gmail.com 